\title{
Organogels Derived from Tetranitrated Crown Ethers
}

\section{Steven J. Langford ${ }^{*}$, Melissa J. Latter, Vei-Lin Lau, Lisandra L. Martin and Adam Mechler}

School of Chemistry, Monash University, Clayton Victoria Australia 3800.

Steven.Langford@sci.monash.edu.au

\section{Supporting Information}

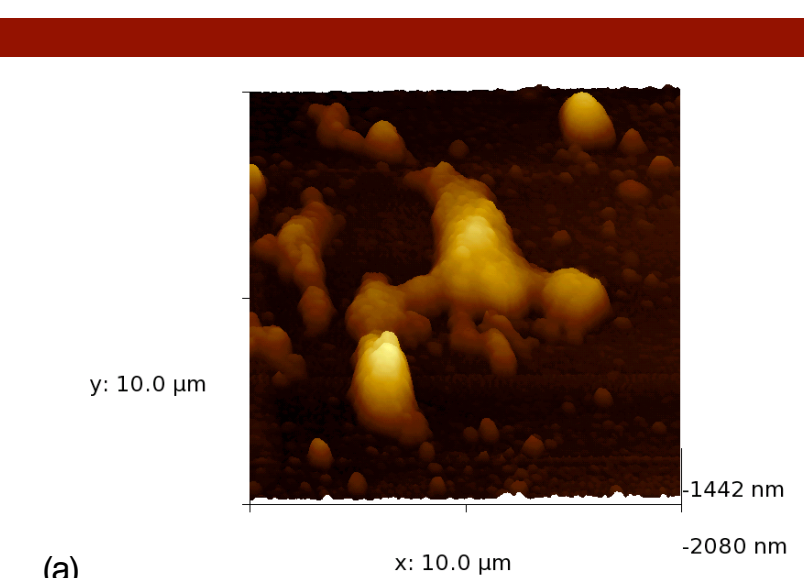

(a)

(b)

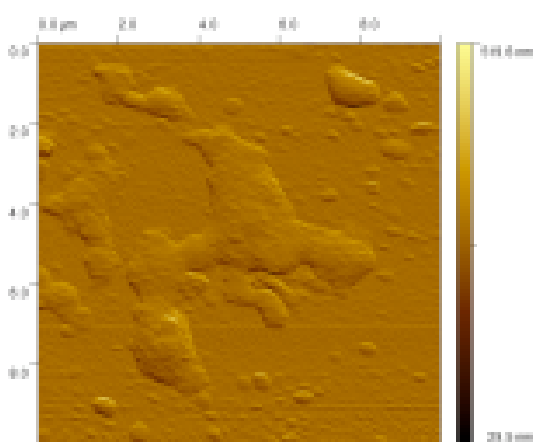

(c)

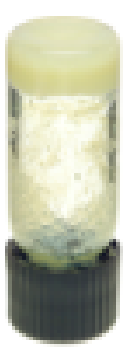

Figure S1. AFM images of $\mathbf{3}$ on glass side (a) local contrast enhanced, (b) surface gradient. (c) Photograph of $\mathbf{3}$ showing gel formation which remains stable upon vial inversion 